\section{The Invention of the Biblical Scholar: A Critical Manifesto, by Stephen D. Moore and Yvonne Sher- wood}

Minneapolis: Fortress Press, 20I I | xiii + I38 pages | ISBN: 97808006-9774-7 (softback) \$22.00

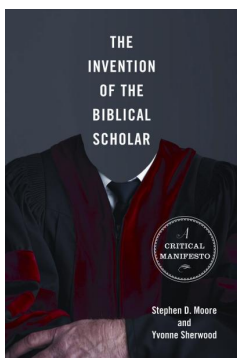

Stephen D. Moore and Yvonne Sherwood's Manifesto is a revision and expansion of three articles published in Biblical Interpretation in 20I0. The point of departure for the articles was a joint AAR/SBL session on the "After Theory" debate-concerning the widely rumoured death of Critical Theory and postmodernism. The book shifts focus to the much broader issue of how the origins of Biblical Studies continue to determine and delimit the discipline's methodologies and concerns. In particular, the authors ask the genealogical question, "why did the 'criticism' in biblical criticism resolutely and exclusively come to take the form of historical criticism" ( $\mathrm{x}$ ) and, conversely, what other forms might it have taken, and, thus, might it take in the future?

In addressing these questions, Moore and Sherwood do not resort to that popular but false gospel which proclaims literary criticism as the saviour of a discipline totally corrupted by a slavish and legalistic adherence to historical criticism. They argue instead that the introduction of literary criticism into Biblical Studies, which became significant from the I970s onwards, in fact perpetuated the same Enlightenment project which historical criticism had commenced. Within Biblical Studies, literary criticism was "largely dedicated to the retrieval of the Bible as a supreme work of human artistry" (xi), a goal which was not dissimilar from that of many Enlightenment philosophes. With this reframing of the debate between historical and literary criticswhich has effectively reached a stalemate in Biblical Studies-Moore and Sherwood introduce a fresh way to view the discipline in its past incarnations and future possibilities. One of the principal future roles for Biblical Studies, they contend, should be the analysis of the discipline's own role in the development of "the Cultural Bible" - a term used by Jonathan Sheehan to refer to the Bible as it was purportedly transformed from sacred text into an object of philological, historical, archaeological, and linguistic inquiry, at the close of the eighteenth and beginning of the nineteenth centuries. Moore and Sherwood's contention is that traditional historical-critical and more recent literary approaches to the Bible should make room for self-reflexive meta- 
criticism. Analysis of the emergence of early Israel or the early Church should be joined by studies of the emergence of the discipline itself and investigations of ancient Near Eastern and Greco-Roman culture should give way to investigations of the role of Biblical Studies in the formation of the national cultures of modern Germany and England.

This analysis of the path that Biblical Studies originally took, Moore and Sherwood propose, should be accompanied by a reconsideration of the paths which the discipline bypassed in order to get there. They argue in particular that Biblical Studies should recover the philosophical and especially ethical considerations which comprised an integral part of early modern biblical criticism before it congealed, in the late eighteenth century, into "Biblical Studies." In order to do so, the discipline should take advantage of the "turn to religion" within recent philosophy, including the topics that has again opened up, such as the human (versus the inhuman, the divine, the animal), the secular (versus the religious), and the universal (versus the particular). Biblical Studies should return philosophy's favour and turn to philosophy, or at least to those strands of philosophy which have recently displayed a renewed interest in "religious" questions.

The combined wit and insight of Moore and Sherwood ensures that there is seldom a dull moment in this punchy and programmatic Manifesto. There are more than a few incisive, if not immaculate, conceptions produced by their fertile union, and while the book, and genre of manifesto, is brief, suggestive, and inspiring of possibilities, rather than exhaustive in detail, even the most theory-averse biblical scholar should find something rewarding within its pages. Moore and Sherwood commence, in Chapter I, "Theory and Methodolatry," with a discussion of the decline of Critical Theory in the Humanities, a decline that the authors suspect has hardly registered in the field of Biblical Studies, given its failure to make a substantial impact there in the first place: "theory in Biblical Studies is approximately the size of Tobago or the Falkland Islands" (9). Although they acknowledge that there are increasing numbers of graduate students who are "fluently bilingual" in Critical Theory and Biblical Studies, they note that Critical Theory circulates mainly outside of mainstream Biblical Studies, turning up "in the Theory-ghettos of the Society of Biblical Literature annual meeting" (I I). Their discussion of the central issues in the "After Theory" debate serves to highlight some of the key differences in the respective natures of Biblical and Literary Studies. For example, while in Literary Studies there was considerable resistance to the allegedly "cold-blooded" method and minutiae sometimes associated with Critical Theory, the authors argue that a substantially similar method- 
ology is fetishized within Biblical Studies and its obsession with minutiae is applauded. The authors also argue that the reason "methodology has long been the sine qua non of Biblical Studies as an academic discipline" is it allows practitioners "to keep our discourse on the Bible from being subjective, personal, private, pietistic, pastoral, devotional, or homiletical," maintaining the facade of an academic boundary to the discipline (40). But the discipline's obsession with method makes for "a mountainous excess of dull and dreary books, essays, and articles," the content of which Moore and Sherwood parody with the exasperated voice of experience: "here, first, in numbing dry detail is my method; now watch and be amazed while I apply it woodenly to this unsuspecting biblical text" (40-4I).

In Chapter 2, "The Invention of the Biblical Scholar," the authors turn to the heart of their subject matter: "the historical and cultural forces that ... formed the discipline itself" (43). Moore and Sherwood document the importance, during the late seventeenth and eighteenth centuries, of the ethical questions raised by biblical texts. Biblical criticism in this period, they contend, was less interested in literary tensions than in the disjunction between morality and biblical (im)morality, and the Manifesto discusses representatives of this tendency, including Immanuel Kant, Pierre Bayle, Anthony Ashley-Cooper (third Earl of Shaftesbury), Thomas Chubb, and Thomas Morgan. The emergence of Biblical Studies as a distinct discipline in the late eighteenth and nineteenth centuries, they claim, saw a shift in the centre of biblical criticism from ethical to historical concerns. Where biblical immorality continued to be dealt with, it was done in a masked way, as in Wellhausen's documentary hypothesis, where the literary distinction of Yahwistic and Priestly sources enshrined the Enlightenment's ethical-religious fantasy of an originally pure, natural, and moral religion and its equally fantastic converse of a corrupt clerical sedimentation. The resulting removal of ethical and theological categories as proper matters of critical inquiry "ensured that [the biblical scholar] could be both a skeptic and a believer at one and the same time" (6I). For it became not only permissible but also orthodox to criticise the historicity of the Bible; conversely, an attempt to critique the Bible's theology or ethics was seen as both academically and religiously heterodox. And so Albert Schweitzer is remembered in Biblical Studies for his critique of Jesus as a mistaken apocalyptic prophet, but not so much for the ethical implications of his work: that Jesus's moral teachings did not contain timeless principles but, due to their being founded on the mistaken belief in the imminence of the end times, are deeply problematic if not largely useless for building contemporary ethics. Moore and Sherwood acknowledge that 
moral critique of the Bible has returned in the form of the politics of identity (critique from the perspective of women, blacks, subalterns, etc). But they ask whether there is room for moral critique on different grounds: intimate and personal (in a style common within non-biblical literary criticism) as well as universal (à la philosophy).

Chapter 3, "Onward Toward the Past," hits out at anything in Biblical Studies that is still left standing after the critical onslaught of the previous two chapters. Moore and Sherwood first attack the tendency of Biblical Studies to fragment into sub-sub-sub-specializations and its ambivalent investigation of political issues. They deflate the tendency within literary-critical currents of Biblical Studies to wax lyrical about the supposedly unsurpassed artistry of the Bible, and the related tendency in appropriations of cultural studies (and here fits reception history) to overemphasise the influence of the Bible on Western culture, viewing both as continuations of "the Enlightenment project of Biblical Studies - the mission to ensure that the Bible remains relevant to the modern age" (95). Moore and Sherwood amusingly document the banalization of Critical Theory within Biblical Studies, including the routine and naïve caricature of "postmodernism" as the discovery that the subject can have no direct and unmediated access to truth-often in ignorance of the fact that this point had been the topic of philosophical-epistemological discussions for centuries. Yet the authors save their most acerbic criticism (and that is saying something) for reader-response theory, which they contend was embraced by Biblical Studies only to the extent that it was shackled to "the discipline's inbred obsession with the historical author and the historical reader," resulting in reader-response criticism becoming, within Biblical Studies, "an exercise in historical criticism performed in a wig and dark sunglasses" (IOI-2). The authors then provide a series of depressing examples where theory is robbed of its critical edge, replaced by a decaffeinated theorylite variety for use within Biblical Studies.

Chapter 3 ends with an overview of the "second wave" of theory, involving the "turn to religion" by figures such as Jacques Derrida, Alain Badiou, Giorgio Agamben, and Slavoj Žižek. This second wave, note Moore and Sherwood, has seen the return of the "big bad old-fashioned words" such as "universalism, democracy, humanism, religion, faith, belief, Christianity, the messianic, Saint Paul, truth, justice, forgiveness, friendship, the kingdom, the neighbor, hospitality, and even, for God's sake, evil" (I 27). The Bible is often central to these philosophical discussions, given its status as "a key site where foundational, but unsustainable, 'modern' separations were made" in the development of such categories (I 28). The significance of this 
philosophical turn for Biblical Studies gives rise to what is the key proposal in Moore and Sherwood's entire Manifesto: "By engaging anew with the formative history of our discipline, we can investigate and interrogate the process whereby critical discourse on the Bible became a means for the consolidation of certain antitheses foundational to modernity, such as religion and reason, myth and history, theology and philosophy, the cultural and the universal, modern subject and ancient object" (I 28).

Moore and Sherwood are surely right in maintaining that a more thorough investigation of the origins of Biblical Studies, and of its later responses to changing socio-historical contexts, is a desideratum of the discipline, a pressing requirement for a more critical appraisal of its assumptions, methodologies, lines of inquiry, framing of problems, research paradigms, and prevailing conclusions. This is not to suggest-although the Manifesto might imply as much in its thoroughgoing critique of every other aspect of the discipline-that we leave the study of the Bible behind in order to study the construction of Biblical Studies, as Timothy Fitzgerald and Russell McCutcheon have proposed in respect of religion and Religious Studies. If the modern study of the Bible has been implicated in nation-building, colonisation, gender-construction, political programmes, and, more generally, the development of modern culture - as indeed it has been-then there is all the more reason, not less, to radically reconsider and reframe old historicalcritical questions and re-evaluate literary-critical ones. I would suggest that any investigation in Biblical Studies - whether of the origins of Israel or the Church, of New Testament responses to empire, of Paul's reconfiguration of the symbols of Judaism, or of John Milton's use of the Bible-requires a dual rather than an either-or approach. What is required is a critical attitude to biblical literature and its contexts which is accompanied by a self-critical attitude to the ways in which Biblical Studies has been and is carried out, and thus how it has structured and limited that biblical criticism. For, as Moore and Sherwood astutely observe, "a discipline's myth of origins powerfully predetermines its practice" (I30).

In this connection, Moore and Sherwood might have been more critical of the conclusions reached by Sheehan in The Englightenment Bible (Princeton University Press, 2005). For Sheehan sweeps up a great diversity of responses to the Bible during the period of the emergence of modern Biblical Studies into his overarching scheme of a transformation of the Bible from religious to cultural artefact. Yet the modern scholarly approach to the Bible was not only more complex than Sheehan describes but was also imprinted 
by decidedly religious factors. The new philological and historical methods used to study the Bible introduced techniques employed in the more profane sciences; but their methods were often overtly apologetic-to affirm and buttress faith in response to the challenges of modernity. As Suzanne Marchand argues in German Orientalism in the Age of Empire (Cambridge University Press, 2009), there has also been a tendency to overemphasise the influence of philosophy and secular concerns in the nineteenth century, and conversely a tendency to underemphasise the continued influence of theology and religion. Similar results are reached by Urs App in The Birth of Orientalism (University of Pennsylvania Press, 2010), in respect of the early Enlightenment period. The historical-critical questions which were framed at the origins of the discipline of Biblical Studies were much more religious than Sheehan allows. Because Moore and Sherwood essentially endorse Sheehan's thesis, and despite their recognition of the return to religion in other disciplines (philosophy especially), they tend to underestimate the extent to which Biblical Studies from its inception has been the practice of religion in the veil of modernity.

But in raising such issues, I am in fact beginning to take up Moore and Sherwood's challenge to reconsider the origins of Biblical Studies and affirm the legitimacy of their challenge. And I find their vision to be an exciting and important one, full of potential for the future of Biblical Studies. Moreover, a turn to the big questions - to philosophy, ethics, and religion-is a fine way to sidestep many of the current pitfalls of both historical and literary criticism. My one major reservation is that, given the increasingly conservative and evangelical nature of Biblical Studies, such a turn would inevitably result in a preponderance of trite, reactionary, and pious sermonising. Of course, it need not. Within biblical reception, a philosophical turn should require a move past the current focus on cataloguing the influence and effects of the Bible, beyond even the detailed accounts of how the Bible has been applied or used within various historical and contemporary contexts, to an adequate theorization of such phenomena which utilises and develops relevant Critical Theory in both its first and second waves alongside theoretical work produced within other academic disciplines and fields. My hope, then, is that the challenge issued by Moore and Sherwood is widely and enthusiastically taken up.

Deane Galbraith University of Otago 